$\xi=$ 圆

\title{
Slip Flow of a Nanofluid Over a Stretching Cylinder with Cattaneo-Christov Flux Model: Using SRM
}

\author{
Gangadhar $K^{1}$, Venkata Ramana ${ }^{2}$, Dasaradha Ramaiah ${ }^{3}$ and B. Rushi Kumar ${ }^{4 *}$ \\ ${ }^{1}$ Department of Mathematics, Acharya Nagarjuna University, Ongole, Andhra Pradesh-523001,India \\ ${ }^{2}$ Deparment of Mathematics, NRI Institute of Technology, Guntur, Andhra Pradesh-522438, India \\ ${ }^{3}$ Deparment of Mathematics, Dhanekula Institute of Engineering and Technology, Ganguru-521139, Andhra Pradesh, India \\ ${ }^{4}$ Department of Mathematics, School of Advanced Sciences, VIT, Vellore-632014,TN, India \\ *Corresponding author E-mail: rushikumar@vit.ac.in
}

\begin{abstract}
This article represents a numerical investigation of heat transfer and slip flow of a nanofluid over a stretching cylinder in magnetic field. In order to explore the heat transfer characteristics Cattaneo-Christov flux model is utilized in place of Fourier's law. By using, suitable transformations, the governing partial differential equations are changed into non-linear ordinary differential equations. A numerical method, known as, spectral relaxation method is used to solve these equations. By using pictorial graphs, the relevant physical parameters that appear in temperature and velocity distributions are analytically discussed. Various types of nanoparticles like $\mathrm{Alumina}\left(\mathrm{Al}_{2} \mathrm{O}_{3}\right)$, Titanium oxide $\left(\mathrm{TiO}_{2}\right)$, Copper $(\mathrm{Cu})$ and Silver $(\mathrm{Ag})$ with water as their base fluid has been assumed. It was identified that absolute value of skin friction coefficient and Nusselt number increases as each of nanoparticle volume fraction or Reynolds number increases. Temperature profile goes up in a faster way in Fourier's law case than Cattaneo-Christov heat flux model. It is also found that the choice of copper (for large values of nanoparticle volume fraction) and alumina (for small nanoparticle volume fraction) leads to highest cooling performance in solving this problem. In order to examine the accuracy of the method, thorough comparison has been made with some previous results.
\end{abstract}

Keywords: MHD, Slip flow, Cattaneo-Christov heat flux model, Stretching cylinder, SRM.

\section{Introduction}

It is known fact that Choi [1] was the first person to coin the term "nanofluid" that means the fluid in which nano-scale particles are pendant inside the basic fluid with low-level thermal conductivity, for example, oils, ethylene glycol, water and so on [2]. In recent years, the concept of nanofluid is proposed as a route for surpassing the performance of heat transfer rate in liquids. The material with sizes of nanometers consists of unique chemical and physical properties [3]. Fluids can flow smoothly through micro-channels not clogging metals as they are small enough and behave like liquid molecules [4]. This fact has enticed many researchers 16] and helped them to investigate the heat transfer characteristics in nanofluids. They also found that, the effective thermal conductivity of the fluids increases appreciably and enhances the heat transfer characteristics in the presence of nanoparticles in the fluids. A good number of articles are found on this topic [17-22], and book by Das et al. [4]. Recently, Gangadher et al. [23] investigated the Newtonian heating impact on MHD micrpolar nanofluid over a permeable stretching shrinking sheet. They assumed titanium oxide $\left(\mathrm{TiO}_{2}\right)$, alumina $\left(\mathrm{Al}_{2} \mathrm{O}_{3}\right)$ and copper $(\mathrm{Cu})$ as water based nanofluids.

In olden days heat transfer is addressed mostly using classical Fourier's law of heat conduction [24]. Energy equation via Fourier's law is parabolic. It also shows that the entire system is instantly affected by the initial perturbation. This issue has been controlled through with the thermal relaxation time in the Fourier's law (see Cattaneo [25]). Energy equation is subjected to CattaneoChristov heat flux that results hyperbolic partial differential equation [26, 27]. Christov [28] developed the analysis of Cattaneo [25] by presenting thermal relaxation time and using Oldroyd's upper convected derivatives for the material-invariant formulation. Han et al. [29] examined Cattaneo-Christov heat flux in the stretched flow of Maxwell fluid over a surface with constant thickness. Thermal conductivity of liquid taken as assumed constant. Straughan [30] used Cattaneo-Christov model for thermal convection in an incompressible flow of viscous fluid. Ciarletta and Straughan [31] are discussed the structural stability and uniqueness of the Cattaneo-Christov equations. Cattaneo-Christov heat flux in MHD flow of an Oldroyd-B fluid over a stretching surface with homogeneous/heterogeneous reactions is used by Hayat et al. [32]. The effect of Cattaneo - Christov heat flux in the stretched flow over a variable thick surface is explored by Hayat et al. [33]. Mustafa et al. [34] analyzed that the non-linear thermal radiation inspires the rotating flow of magnetite-water nanofluid by a stretched sheet. Waqas et al. [35] examined that in the presence of variable thermal conductivity, Burgers fluid flow with Cattaneo-Christov heat flux model. Abbasi and Shehzad [36] examined that three dimensional flow of Maxwell fluid with Cattaneo-Christov heat flux model. investigated Jeffrey fluid flow with Cattaneo-Christov heat flux because of variable thick surface investigated by Hayat et al. [37] . Li et al. [38] examined heat transfer in MHD viscoelastic flow with Cattaneo-Christov heat flux model. Hayat et al. [39] analyzed stagnation point flow of Maxwell fluid with Cattaneo-Christov heat flux and homogeneous-heterogeneous response. 
Anomalous convection diffusion with Cattaneo-Christov heat flux because of coupling transport of cells is inspected by Liu et al. [40]. To investigate Cattaneo-Christov heat flux Reddy et al. [41] assumed three various geometries in presence of cross diffusion impacts. Hayat et al. [42] inspected two-dimensional stratified flow of Eyring-Powell fluid with Cattaneo-Christov heat flux. Effect of Cattaneo-Christov heat flux is put forth by Tanveer et al. [43]. Muhammad and Nadeem [44] reported Maxwell fluid flow using Cattaneo- Christov heat flux theory. Hayat et al. [45] explored numerical results for flow between two stretchable rotating disks with Cattaneo-Christov heat flux model. Recently, Raju et al. [46] investigated the MHD flow over a stretched cylinder with Cattaneo-Christov heat flux model with injection or suction.

It should be noted that no-slip conditions are employed in all the attempts mentioned above. Be that as it may, in a micro-electro mechanical system and some coated surfaces like as Teflon, resist adhesion, the no-slip boundary condition is not applicable. Hence, the slip phenomenon must be acknowledged. The fluids with the slip phenomenon at the boundary have important technological applications like polishing of artificial heart valves and internal cavities. A lot of models explain the relation between the velocity gradient normal to the surface and the tangential component of the velocity at the surface. Thus, another dimension is added to the above study by acknowledging the impacts of partial slip at the stretching wall. A significant number of scientists at present have focused on the flow and heat transfer analysis at micro-scale with slip effects. Turkyilmazoglu[47] has got good a number of solutions for the heat and mass transfer analysis of viscoelastic fluids due to a stretching surface with slip conditions.

Freidoonimehr et al. [48] has given the MHD stagnation point flow towards a porous rotating surface with the velocity slip condition. Turkyilmazoglu[49] performed an investigation to learn the characteristics of heat and mass transfer in the viscous flow towards a stretching surface with velocity and thermal slip conditions. Mukhopadhyay [50] examined those slip effects in a porous stretchable surface with the thermal radiation in MHD flow. Malvandi et al. [51] numerically investigated the two-dimensional stagnation point flow of a nanofluid induced by a stretchable sheet with Navier's slip condition. Turkyilmazoglu [52] acknowledged the MHD slip flow of an electrically conducting non-Newtonian fluid towards a shrinking surface. The slip effect in the mixed convective boundary layer flow over a flat plate was reported by Bhattacharyya et al. [53]. Rashidi et al. [54] presented the numerical effect of magnetic, slip, and relative temperature difference on the velocity and temperature field in the flow by a rotating disk. The variable properties over a rotating disk were analyzed in the entropy era. Mukhopadhyay [55] examined the MHD axisymmetric flow of a viscous fluid by a stretched cylinder heat transfer. The partial slip effect was calculated by the flow analysis. Recently, Kiran Kumar et al. [56] studied the three dimensional slip flow in suspended carbon nano tubes through a slandering sheet in the presence of heat source.

The main aim of this paper is to steady the slip flow and heat transfer of a nanofluid due to the stretching cylinder in the presence of Cattaneo-Christov heat flux model. Cattaneo-Christov heat flux model which is modified version of the established stands of Fourier's law is used as a part of this work to investigate the insight of heat transfer phenomena. The nanofluid model proposed by Tiwari and Das [6] is used. Various types of nanoparticles like alumina $\left(\mathrm{Al}_{2} \mathrm{O}_{3}\right)$, silver $(\mathrm{Ag})$, copper $(\mathrm{Cu})$ and titanium oxide $\left(\mathrm{TiO}_{2}\right)$ with water as their base fluid has been assumed. For accuracy, the modeled differential equations are solved numerically using Spectral relaxation technique. The effects of the parameters governing the issue are thoroughly discussed and analyzed.

\section{Mathematical Formulation}

Consider the steady laminar nanofluid flow of an incompressible electrically conducting fluid (with electrical conductivity $\sigma$ ) caused by a stretching tube with radius $a$ in the axial way in a fluid extremely at rest as occurred in Fig. 1, where $z$-axis is deliberate along the axis of the tube and $r$-axis is measured in the radial way. Cattaneo-Christov model for heat conduction is utilized to investigate the heat transfer. It is considered that the surface of the tube is at constant temperature $T_{w}$ and the ambient fluid temperature is $T_{\infty}$, where ${ }_{T_{w}>T_{\infty}}$ (heated cylinder). We also consider that the uniform magnetic field with intensity of $B_{0}$ acts in the radial way and the impact of the induced magnetic field is insignificant, which is applicable when the magnetic Reynolds number is small.

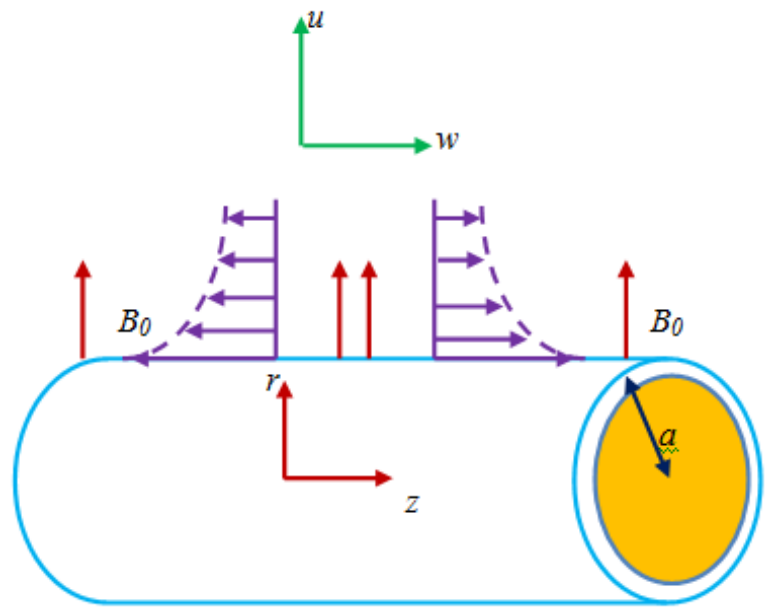

Fig. 1: Physical model and coordinate system

The viscous dissipation, Ohmic heating and Hall effects are abandoned as they are also considered to be small. The field is a water based nanofluid consisting various types of nanoparticles: Ag, $\mathrm{Al}_{2} \mathrm{O}_{3}, \mathrm{Cu}$ and $\mathrm{TiO}_{2}$. It is considered that the base fluid and the nanoparticles are in thermal equilibrium and no slip occurs between them. The thermo physical properties of the nanofluid are given in table 1. Under these considerations, and the following nanofluid model planned by Tiwari and Das (2007), the governing equations are

$$
\frac{\partial(r w)}{\partial z}+\frac{\partial(r u)}{\partial r}=0
$$

$\rho_{n f}\left(w \frac{\partial w}{\partial z}+u \frac{\partial u}{\partial r}\right)=\mu_{n f}\left(\frac{\partial^{2} w}{\partial r^{2}}+\frac{1}{r} \frac{\partial w}{\partial r}\right)-\sigma_{n f} B_{0}{ }^{2} w$

$\rho_{n f}\left(w \frac{\partial u}{\partial z}+u \frac{\partial u}{\partial r}\right)=-\frac{\partial p}{\partial r}+\mu_{n f}\left(\frac{\partial^{2} u}{\partial r^{2}}+\frac{1}{r} \frac{\partial u}{\partial r}-\frac{u}{r^{2}}\right)$

$$
w \frac{\partial T}{\partial z}+u \frac{\partial T}{\partial r}+\gamma\left(\begin{array}{l}
u^{2} \frac{\partial^{2} T}{\partial r^{2}}+w^{2} \frac{\partial^{2} T}{\partial z^{2}}+2 u w \frac{\partial^{2} T}{\partial z \partial r} \\
+\left(w \frac{\partial u}{\partial z}+u \frac{\partial u}{\partial r}\right) \frac{\partial T}{\partial r} \\
+\left(w \frac{\partial w}{\partial z}+u \frac{\partial w}{\partial r}\right) \frac{\partial T}{\partial z}
\end{array}\right)=\frac{k_{n f}}{\left(\rho C_{p}\right)_{n f}}\left(\frac{\partial^{2} T}{\partial r^{2}}+\frac{1}{r} \frac{\partial T}{\partial r}\right)
$$

Subject to the boundary conditions

$u=u_{w}, w=w_{w}+L_{1} \frac{\partial w}{\partial r}, T=T_{w}+L_{2} \frac{\partial T}{\partial r}$ at $r=a$

$w \rightarrow 0, T \rightarrow T \quad$ as $r \rightarrow \infty$ 
Here, $w_{w}=2 c z$, where $c$ is a positive constant, $T$ is the fluid temperature, $\mathrm{u}$ and $\mathrm{w}$ are the velocity components along the $r$ and $z$-axes correspondingly. The effective dynamic viscosity $\mu_{n f}$, the effective density $\rho_{n f} \gamma$ the thermal relaxation time, the heat capacitance $(\rho C p)_{n f}, L_{1}$ and $L_{2}$ the slip and jump coefficients, $\sigma_{n f}$ the conductivity of the fluid and the thermal conductivity of the nanofluid $k_{n f}$ are given as

$$
\begin{aligned}
& \rho_{n f}=(1-\phi) \rho_{f}+\phi \rho \rho_{s}, \mu_{n f}=\frac{\mu_{f}}{(1-\phi)^{2.5}} \\
& \left(\rho C_{p}\right)_{n f}=(1-\phi)\left(\rho C_{p}\right)_{f}+\phi\left(\rho C_{p}\right)_{s} \\
& \sigma_{n f}=(1-\phi) \sigma_{f}+\phi \sigma_{s}, \\
& \frac{k_{n f}}{k_{f}}=\frac{k_{s}+2 k_{f}-2 \phi\left(k_{f}-k_{s}\right)}{k_{s}+2 k_{f}+2 \phi\left(k_{f}-k_{s}\right)}
\end{aligned}
$$

Here $\phi$ is the solid volume fraction.

Following Wang [57] we take the similarity transformations $\eta=(r / a)^{2}, u=-c a(f(\eta) / \sqrt{\eta}), w=2 c f^{\prime}(\eta) z$

$$
\theta(\eta)=\left(T-T_{\infty}\right) /\left(T_{w}-T_{\infty}\right)
$$

Here differentiation with respect to $\eta$ is denoted by prime.

The following ordinary differential equations are obtained by substituting (8) into Eqs. (2) and (4):

$$
\begin{aligned}
& \operatorname{Re} . A_{1} \cdot(1-\phi)^{2.5}\left(f^{\prime 2}-f f^{\prime \prime}\right) \\
& =\eta f^{\prime \prime \prime}+f^{\prime \prime}-M \cdot(1-\phi)^{2.5} f^{\prime} \\
& \frac{1}{\operatorname{Pr}} \frac{A_{3}}{A_{2}}\left(\eta \theta^{\prime \prime}+\theta^{\prime}\right)+\operatorname{Re} f \theta^{\prime}+\operatorname{Re} \lambda\left(f^{2} \theta^{\prime}-f \theta^{\prime} f^{\prime}\right)=0
\end{aligned}
$$

And the boundary conditions (5) - (6) changes as

$$
\begin{aligned}
& f(1)=0, f^{\prime}(1)=1+\alpha_{1} f^{\prime \prime}(1), \theta(1)=1+\alpha_{2} \theta^{\prime}(1) \\
& f^{\prime}(\infty) \rightarrow 0, \quad \theta(\infty) \rightarrow 0
\end{aligned}
$$

Here $\quad M=\sigma_{n f} B_{0}{ }^{2} a^{2} /\left(4 \mu_{f}\right)$ is the magnetic field factor, $\operatorname{Re}=c a^{2} / 2 v_{f}$ is the Reynolds number, $\lambda=2 c \gamma$ is the thermal relaxation factor, $\operatorname{Pr}=\mu_{f}\left(\rho C_{p}\right)_{f} /\left(\rho_{f} k_{f}\right)$ is the Prandtl number, $\alpha_{1}$ is the velocity slip factor, $\alpha_{2}$ is the thermal jump factor and $\mathrm{A}_{1}$, $\mathrm{A}_{2}, \mathrm{~A}_{3}$ are fixed values given by

$$
\begin{aligned}
& A_{1}=(1-\varphi)+\frac{\rho_{s}}{\rho_{f}} \varphi A_{2}=(1-\varphi)+\frac{\left(\rho C_{p}\right)_{s}}{\left(\rho C_{p}\right)_{f}} \varphi, \\
& A_{3}=\frac{k_{n f}}{k_{f}}=\frac{k_{s}+2 k_{f}-2 \varphi\left(k_{f}-k_{s}\right)}{k_{s}+2 k_{f}+2 \varphi\left(k_{f}-k_{s}\right)}
\end{aligned}
$$

Eq. (3) gives the pressure in the form

$$
\frac{P-P_{\infty}}{\rho_{n f} c v_{n f}}=-\frac{\mathrm{Re}}{\eta} \cdot A_{1} \cdot(1-\phi)^{2.5} f^{2}(\eta)-2 f^{\prime}(\eta)
$$

Physical quantities of interest are the Nusselt number $\mathrm{Nu}$ and the skin friction coefficient $C_{f}$, which are defined as
$C_{f}=\frac{\tau_{w}}{\rho_{f} w_{w}{ }^{2}}, \quad N u=\frac{a q_{w}}{k_{f}\left(T_{w}-T_{\infty}\right)}$

Where $q_{w}$ and $\tau_{w}$ are the heat transfer and skin friction from the surface of the cylinder correspondingly, and those are given by

$$
\begin{aligned}
& \tau_{w}=\mu_{n f}\left(\frac{\partial w}{\partial r}\right)_{r=a}, q_{w}=-k_{n f}\left(\frac{\partial T}{\partial r}\right)_{r=a} \\
& (2 z \operatorname{Re} / a) C_{f}=\frac{1}{(1-\phi)^{2.5}} f^{\prime \prime}(1), N u=-2 \frac{k_{n f}}{k_{f}} \theta^{\prime}(1)
\end{aligned}
$$

\section{Solution of the Problem}

With a specific end goal to tackle the conditions (9)-(10) subject to the boundary conditions (11) and (12) the Spectral Relaxation Method (SRM) given by Motsa and Makukula (2013) and Kameswaran et al. (2013) is used. The method uses the GaussSeidel approach to decouple the system of equations. In the system of SRM technique the iteration scheme is obtained as

$f_{r+1}^{\prime}=p_{r}, f_{r+1}(0)=0$

$$
\begin{array}{r}
\eta p_{r+1}^{\prime \prime}+\left(1+\operatorname{Re} A_{1}(1-\Phi)^{2.5} f_{r+1}\right) p_{r+1}^{\prime}-M(1-\Phi)^{2.5} p_{r+1} \\
=\left(\operatorname{Re} A_{1}(1-\Phi)^{2.5}\right) p_{r+1}^{2}
\end{array}
$$

$\eta \theta_{r+1}^{\prime \prime}+\left(1+\operatorname{Pr} \operatorname{Re} \frac{A_{2}}{A_{3}}\left(f_{r+1}-\lambda f_{r+1} p_{r+1}\right)\right) \theta_{r+1}^{\prime}+\left(\operatorname{Pr} \operatorname{Re} \frac{A_{2}}{A_{3}} \lambda f_{r+1}^{2}\right) \theta_{r+1}=0$

The boundary conditions for the above iteration scheme are

$$
\begin{aligned}
& p_{r+1}(0)=1+\alpha_{1} p_{r+1}^{\prime}(0), \theta_{r+1}(0)=1+\alpha_{2} \theta_{r+1}^{\prime}(0) \\
& p_{r+1}(\infty)=0, \theta_{r+1}(\infty)=0
\end{aligned}
$$

With a specific end goal to comprehend the decoupled equations (25) - (27), we use the Chebyshev spectral collocation technique. The computational domain $[0, L]$ is changed to the interval $[-1,1]$ utilizing $\eta=L(\xi+1) / 2$ on which the spectral method is used.

Here $L$ is used to invoke the boundary conditions at $\infty$. The essential thought behind the spectral collocation technique is the introduction of a differentiation matrix $\mathcal{D}$ which is used to estimated the derivatives of the unknown variables at the collocation points as the matrix vector product of the form

$$
\frac{\partial f_{r+1}}{\partial \eta}=\sum_{k=0}^{N} D_{l k} f_{r}\left(\xi_{k}\right)=D f_{r}, l=0,1,2, \ldots \ldots \ldots . N
$$

Where $N+1$ is the number of collocation points (grid points), D $=2 \mathcal{D} / \mathrm{L}$, and $f=\left[f\left(\xi_{0}\right), f\left(\xi_{1}\right), f\left(\xi_{2}\right), \ldots \ldots \ldots f\left(\xi_{N}\right)\right]^{T}$ is represented the vector function at the collocation points. Higherorder derivatives are acquired as powers of $\mathrm{D}$, that is,

$f_{r}^{(p)}=D^{p} f_{r}$ 
where $p$ is the order of the derivative. By implementing the spectral method to equations (25)- (27), we get

$$
\begin{aligned}
& A_{1} f_{r+1}=B_{1}, f_{r+1}\left(\xi_{N}\right)=0 \\
& A_{2} p_{r+1}=B_{2}, \sum_{k=0}^{\bar{N}} D_{\bar{N} k} p_{r+1}\left(\xi_{k}\right)-p_{r+1}\left(\xi_{k}\right)=-1, p_{r+1}\left(\xi_{0}\right)=0
\end{aligned}
$$

$$
A_{3} \theta_{r+1}=B_{3}, \sum_{k=0}^{\bar{N}} D_{\bar{N} k} \theta_{r+1}\left(\xi_{k}\right)-\theta_{r+1}\left(\xi_{k}\right)=-1, \theta_{r+1}\left(\xi_{0}\right)=0
$$

Here,

$$
\begin{aligned}
& A_{1}=D, B_{1}=p_{r+1} \\
& A_{2}=\eta D^{2}+\operatorname{diag}\left(1+\operatorname{Re} A_{1}(1-\Phi)^{2.5} f_{r+1}\right) D-M(1-\Phi)^{2.5} I \\
& B_{2}=\left(\operatorname{Re} A_{1}(1-\Phi)^{2.5}\right) p_{r+1}^{2} \\
& A_{3}=\eta D^{2}+\operatorname{diag}\left(1+\operatorname{Pr} \operatorname{Re} \frac{A_{2}}{A_{3}}\left(f_{r+1}-\lambda f_{r+1} p_{r+1}\right)\right) D- \\
& \operatorname{diag}\left(\operatorname{Pr} \operatorname{Re} \frac{A_{2}}{A_{3}} \lambda f_{r+1}^{2}\right) I, B_{3}=0
\end{aligned}
$$

In equations (36)-(37), I, [] are an identity matrix and diagonal matrix respectively, all of size $(N+1) \times(N+1)$ where $N$ represents the number of grid points, $f, p$ and $\theta$ are the values of the functions $f, p$ and $\theta$ respectively, when calculated at the grid points and the iteration number is represented by subscript $r$. The initial guesses to begin the SRM technique for equalities (28)(29) are chosen as

$$
f_{0}(\eta)=\frac{1}{1+\alpha_{1}}\left(1-e^{-\eta}\right), p_{0}(\eta)=\frac{1}{1+\alpha_{1}} e^{-\eta}, \theta_{0}(\eta)=\frac{1}{1+\alpha_{2}} e^{-\eta}
$$

which are randomly chosen functions that satisfy the boundary conditions. The iteration is repetitive until convergence is achieved. The convergence of the SRM technique is characterized in terms of the infinity norm as

$$
E r=\operatorname{Max}\left(\left\|f_{r+1}-f_{r}\right\|,\left\|p_{r+1}-p_{r}\right\|,\left\|\theta_{r+1}-\theta_{r}\right\|\right)
$$

Accuracy of the scheme is recognized by increasing the number of collocation points $N$ until the solutions are consistent and additionally increases do not change the value of the solutions.

\section{Results and Discussion}

By using the spectral relaxation method, the non-linear ordinary differential equations (9) and (10) which are subjected to the boundary conditions (11) and (12), were solved numerically. Four different types of nanoparticles namely Silver $(\mathrm{Ag})$, Copper $(\mathrm{Cu})$, Titanium oxide $\left(\mathrm{TiO}_{2}\right)$ and Alumina $\left(\mathrm{Al}_{2} \mathrm{O}_{3}\right)$ with water as base fluid are taken. The thermo physical properties of fluid water and nanoparticles $\mathrm{Ag}, \mathrm{Cu}, \mathrm{TiO}_{2}$ and $\mathrm{Al}_{2} \mathrm{O}_{3}$ are represented in table 1 . The Prandtl number for the base fluid i.e. water is kept constant at 7. It is worthy to mention that this study is minimized to those of a viscous or regular fluid when $\Phi=0$. Figure 2 demonstrates the temperature profile for various nanoparticles. It can be obsered that temperature profile for nanoparticles increses gradually from the surface of the stretching sheet. The fluid temperature in the case of $\mathrm{Ag}$-water nanofluid is less than those in $\mathrm{Al}_{2} \mathrm{O}_{3}$-water, $\mathrm{Cu}$ water and $\mathrm{TiO}_{2}$-water nanofluid. The physics behind these outcomes is true because thermal conductivity of Silver $(\mathrm{Ag})$ is higher than those in Copper $(\mathrm{Cu})$, Alumina $\left(\mathrm{Al}_{2} \mathrm{O}_{3}\right)$ and Titanium oxide $\left(\mathrm{TiO}_{2}\right)$. Figure 3 and 4 represents the effect of transverse magnetic field parameter $M n$ on the nanofluid velocity $f^{\prime}(\eta)$ and temperature distribution $\theta(\eta)$. Figure 3 depicts an increase of magnetic field parameter $M n$ which tends to decrease the nanofluid velocity in the case of $C u$-water when $M n=0,0.5,1,1.5$ and 2 with $P r=$ 7, $\Phi=0.1, \operatorname{Re}=1, \alpha_{1}=\alpha_{2}=0.1 \& \lambda=0.5$. This clearly indicates that the transverse magnetic field contradicts the transport phenomena. This is because of the fact that variation of $M n$ leads to variation of the Lorentz force. Due to magnetic field, the Lorentz force produces more resistance to transport phenomena. In all cases, the velocity vanishes at some huge distance from the surface of the cylinder. The temperature of nanofluid is discovered of the cylinder increases. (Fig. 4). Figure 5 and 6 exemplify the effect of nanoparticle volume fraction $\Phi$ on the nanofluid velocity and temperature profiles, respectively, in the case of $\mathrm{Cu}$ nanoparticle and water base fluid $(\operatorname{Pr}=7)$ when $\Phi=0,0.05,0.1$ and 0.2 with $M n=0.5, \quad P r=7, \quad \operatorname{Re}=$ $1, \alpha_{1}=\alpha_{2}=0.1 \& \lambda=0.5$. It is observed that, when the nanoparticles volume fraction accelerates, the nanofluid velocity decelerates and temperature increases. These figures illustrate this agreement with the physical behavior. When the volume of nanoparticle increases, the thermal conductivity layer also increases. From figures 7 and 8 , it is worth to mention that the Reynolds number Re indicates the relative importence of the inertia effect when compared to the viscous effect. Thus, both velocity and temperature profiles decrease as Re increase and the increasing $\mathrm{Re}$ in turn leads to increase in the magnitude of the Nusselt number and skin friction coefficient (Fig. tables 6 and 7).

The slip coefficients have a have a great influence on the velocity and temperature as vividly shown in Figure 9 and 10 respectively. The velocity of the fluid decreases with momentum slip constant $\alpha_{1}$. This is because momentum slip enhances the velocity at the fluid-solid boundary. In case of the no-slip condition, the fluid velocity by the side of a solid surface is equivalent to the velocity of the stretching sheet. i.e., $f^{\prime}(0)=\alpha_{1}=0$ while with an increase in slip parameters, the momentum boundary layer thickness decrease. The momentum slip coefficient accelerates the temperature profile and temperature of the fluid increases with momentum slip parameter $\alpha_{1}$. With momentum slip, more heat is transferred which leads to to a reduction in surface temperature that reduces the velocity of the fluid. The velocity curves exhibit the rate of change. The rate of transport decreases with the increasing distance $(\eta)$ which is normal to the sheet. In all cases the velocity vanishes at some large distance from the sheet (at $\eta=15$ ) Figure 11 display the influence of temperature jump factor on dimensionless temperature distribution and other parameters kept at constant $\Phi=0.1, \operatorname{Pr}=7, M n=0.5, R e=1, \alpha_{1}=0.1$ and $\lambda=0.2$. It is noticed from figure (11) that increase in temperature jump parameter from $\alpha=0$ to 1.0 promotes the decrease in the temperature profile. It is undoubtedly understood that the temperature jump between the wall and the nanofluid means the thermal contact resistance which decelerates the amount of heat transfer. Then, we can infer that the slip velocity also has the similar behavior on the velocity near the plate. Due to existence of the temperature jump, various temperature jump parameters lead to various temperatures at the cylinder. Moreover, with the increasing distance from the cylinder, the effect of the temperature jump factor on the temperature becomes smaller.

Figure12 demonstrate the behavior of temperature distribution for higher values of thermal relaxation parameter $\lambda$ for $C u$-water 
based nanofluid with $\Phi=0.1, \operatorname{Pr}=7, M n=0.5, R e=1, \alpha_{1}=0.1$, $\alpha_{2}=0.1$. It is noticed that for higher values of thermal relaxation parameter $\lambda$, the temperature reduces. In fact, thermal relaxation time increases for higher $\lambda$. It implies particles require considerably more time to transfer heat to its neighboring particles and thus parameter fall in. Figure13, delineates the influence of Reynolds number $R e$ and slip velocity factor $\alpha_{1}$ on skin friction coefficient for cu-water based nanofluid and other parameters taken constant as $\Phi=0.1, \operatorname{Pr}=7, M n=0.5, \lambda=0.2$ and $\alpha_{2}=0.1$. Actually, negative sign of skin friction coefficient implies the stretching cylinder implies a dragging force on the nanofluid and positive sign implies the opposite.

From figure 13, it can be observed that the increasing value of Reynolds number increases the size of the skin friction coefficient because it minimizes the velocity profile (see fig.7) and slip velocity decreases the skin friction coefficient. From figure 14, it is observed that both slip velocity and thermal jump factor leads to decrease the Nusselt number. Tables 2 - 5 show the comparison of the present out comes with the previous literature. It is noticed that the obtained outcomes are in agreement with the published work [57, 61]. This comparison acts as a worth noticing measure in giving accurate and efficient result. From Table 2-5 it is observed that magnitude of the skin friction coefficient increases when Nusselt number decreases with the increasing of the magnetic field parameter. This comparison gives nine digits accuracy. Effect of nanoparticle volume fraction $\Phi$ on Nusselt number and the skin friction coefficient is given by [15] when $M n=0.5, R e=1$,

$\alpha_{1}=\alpha_{2}=0.1, \operatorname{Pr}=7, \lambda=0.5$ for various nanofluids $\mathrm{Al}_{2} \mathrm{O}_{3}, \mathrm{Cu}, \mathrm{Ag}$, $\mathrm{TiO}_{2}$ water based nanofluids. The tables show that by using various types of nanofluids, the values of skin friction coefficient and Nusselt number changes. This clearly shows that the nanofluids type will be essential in the cooling and heating process. It is also found that for all values of nanoparticles volume fraction $\phi$, choosing alumina as the nanoparticle leads to the maximum amount of the skin friction coefficient, while choosing silver it leads to the minimum amount of skin friction coefficient. For small values of nanoparticles solid volume fraction $\Phi$, choosing copper as the nanoparticle leads to the maximum amount of Nusselt number, while choosing alumina as the nanoparticcle it leads to the maximum amount of it for large value of $\Phi$. Also, it can be seen that selecting Titanium oxide leads to the lowest amount of Nusselt number. Tables vividly display the behavior of the Nusselt number for various values of thermal relaxation parameter $\lambda$ using various nanofluids. For higher values of $\lambda$, the Nusselt number value decreases.

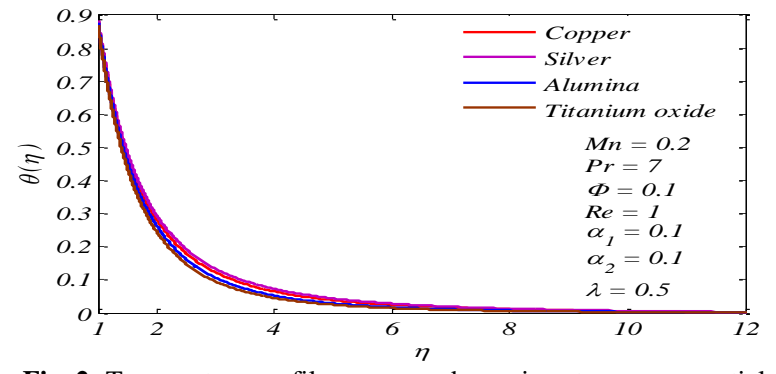

Fig. 2: Temperature profiles $\theta(\eta)$ under various types nanoparticles.

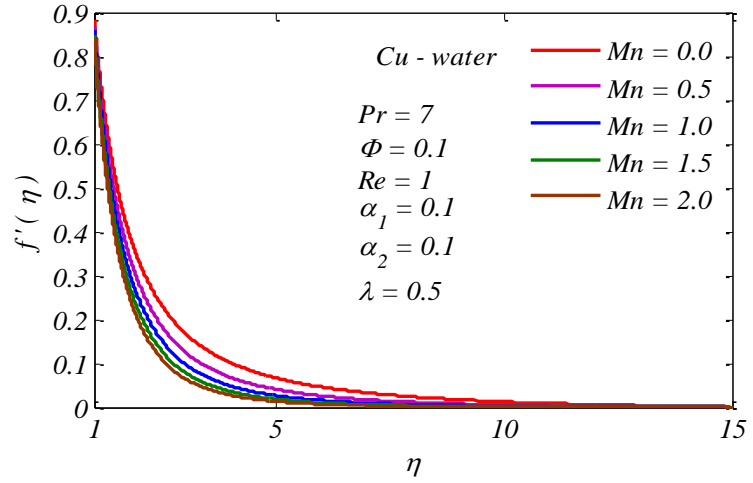

Fig. 3: Velocity profiles $f^{\prime}(\eta)$ under various values of magnetic field parameter $M n$.

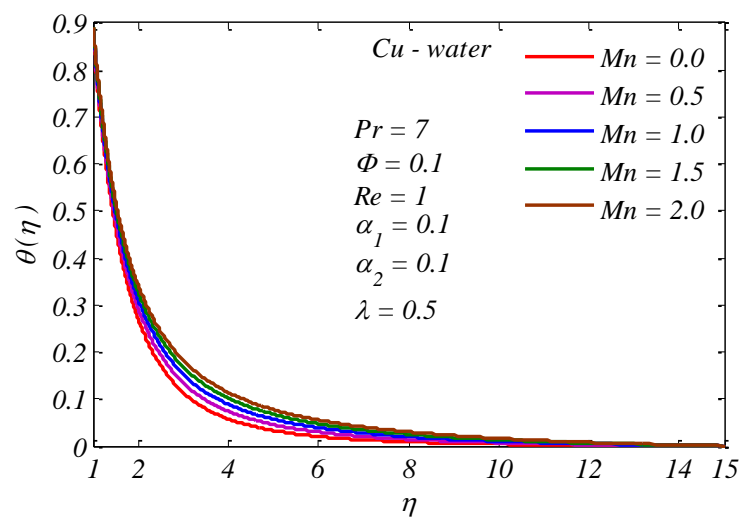

Fig. 4: Temperature profiles $\theta(\eta)$ under various values of magnetic field parameter $M n$.

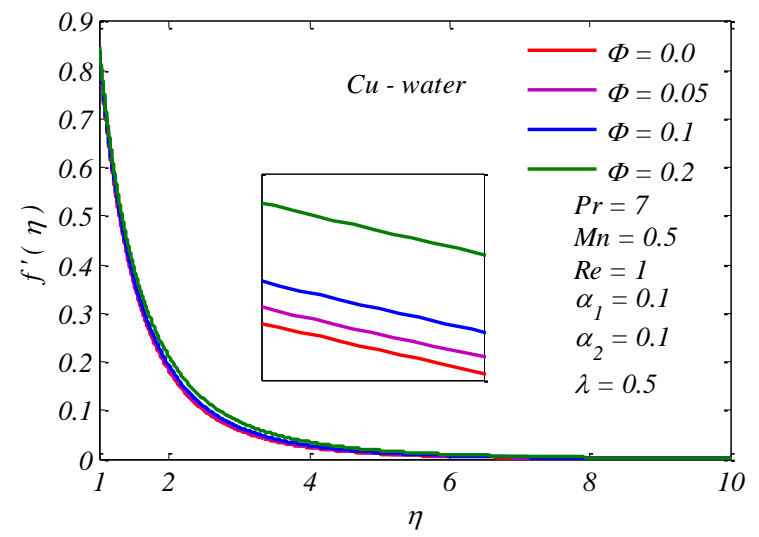

Fig. 5: Velocity profiles $f^{\prime}(\eta)$ under various values of nanoparticle volume fraction $\Phi$.

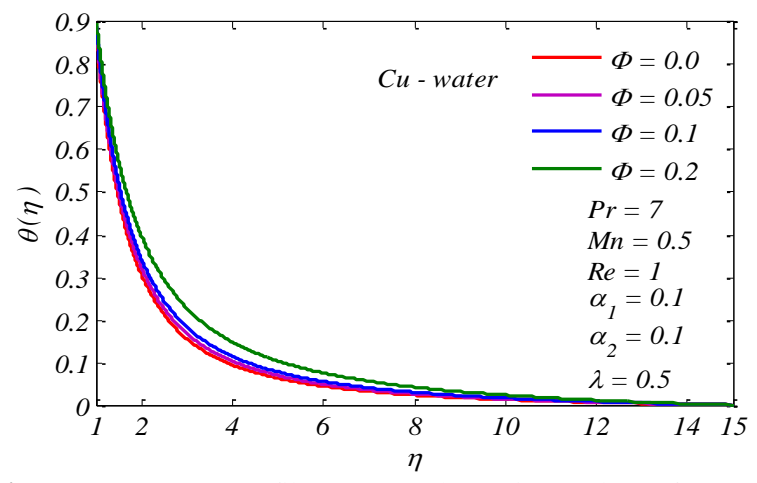

Fig. 6: Temperature profiles $\theta(\eta)$ under various values of nanoparticle volume fraction $\Phi$. 


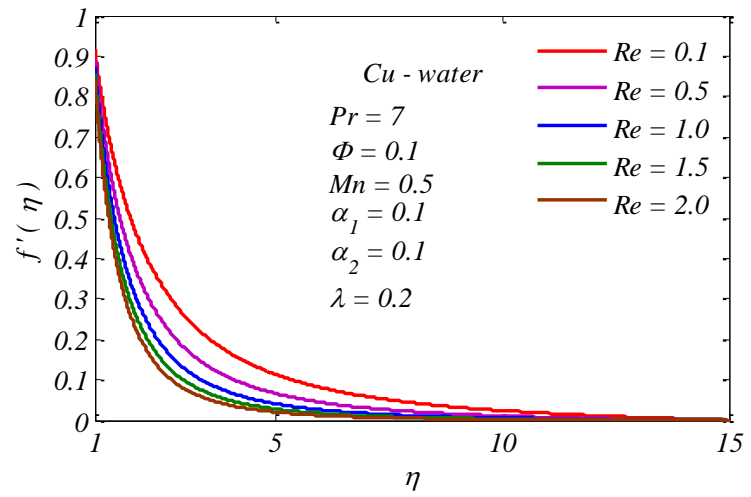

Fig. 7: Velocity profiles $f^{\prime}(\eta)$ under various values of Reynolds number $\operatorname{Re}$.

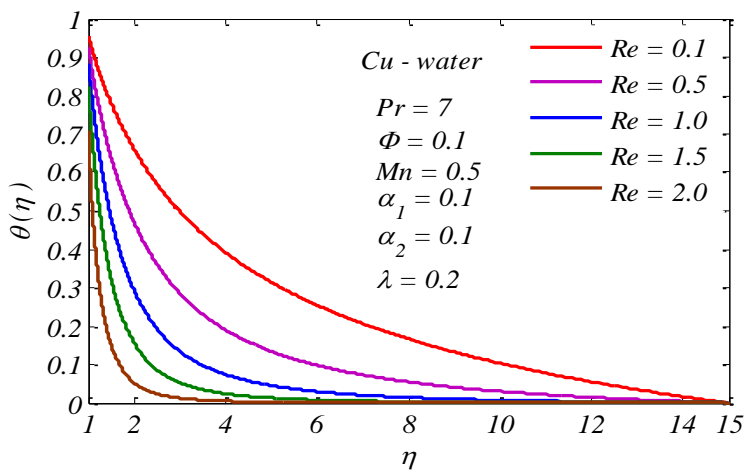

Fig. 8: Temperature profiles $\theta(\eta)$ under various values of Reynolds number $\mathrm{Re}$

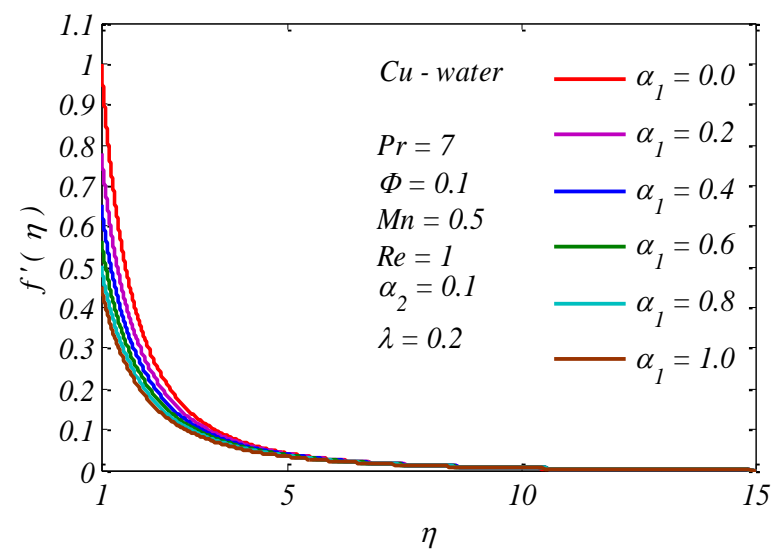

Fig. 9: Velocity profiles $f^{\prime}(\eta)$ under various values of momentum slip parameter $\alpha_{1}$

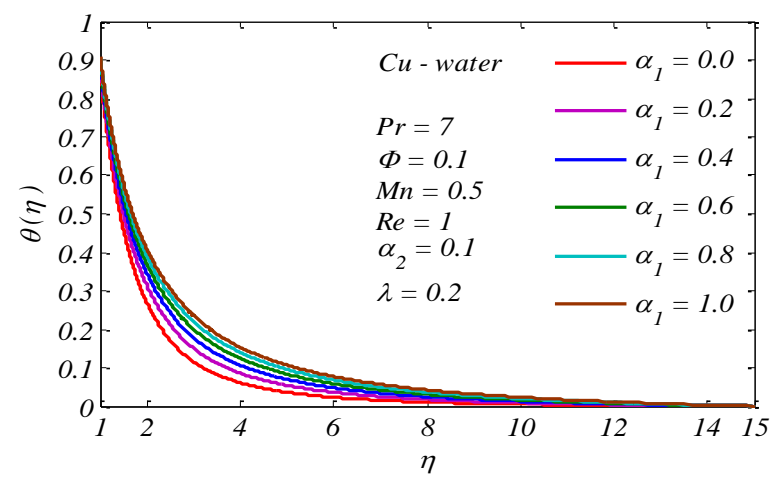

Fig. 10: Temperature profiles $\theta(\eta)$ under various values of momentum slip parameter $\alpha_{1}$

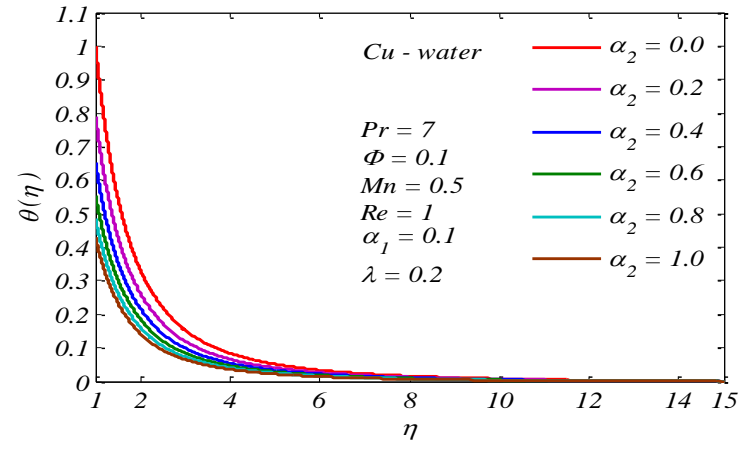

Fig. 11: Temperature profiles $\theta(\eta)$ under various values of thermal slip parameter $\alpha_{2}$

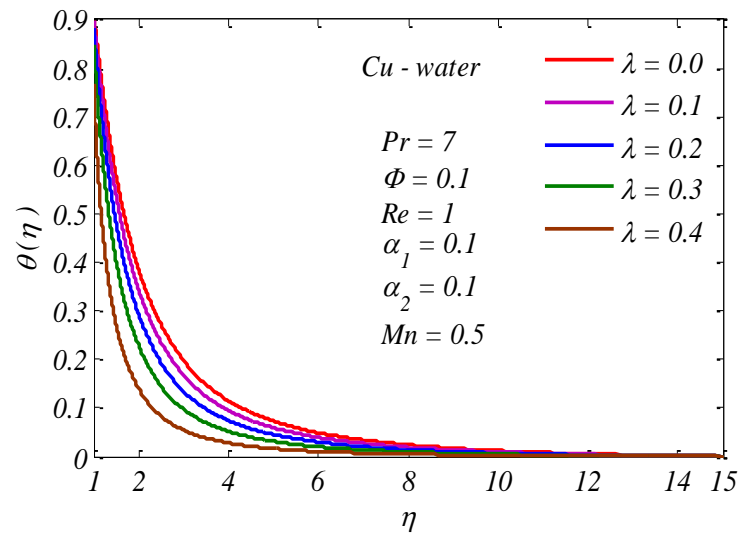

Fig. 12: Temperature profiles $\theta(\eta)$ under various values of thermal relaxation parameter $\lambda$

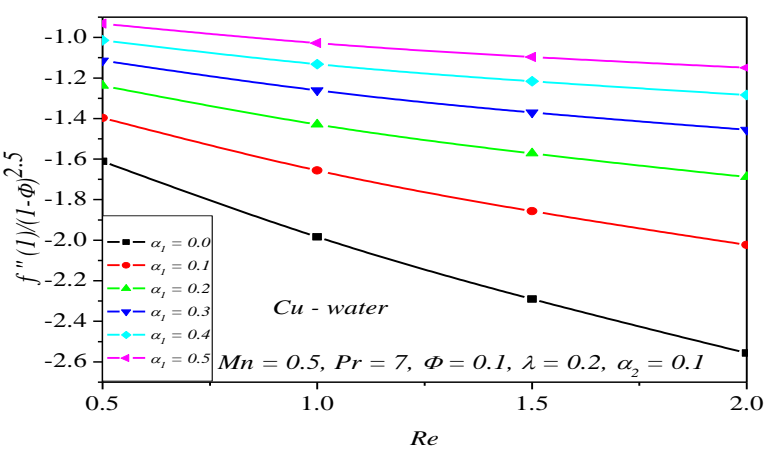

Fig. 13: Skin friction coefficient $\frac{1}{(1-\Phi)^{2.5}} f^{\prime \prime}(1)$ under various values of $\operatorname{Re} \& \alpha_{1}$.

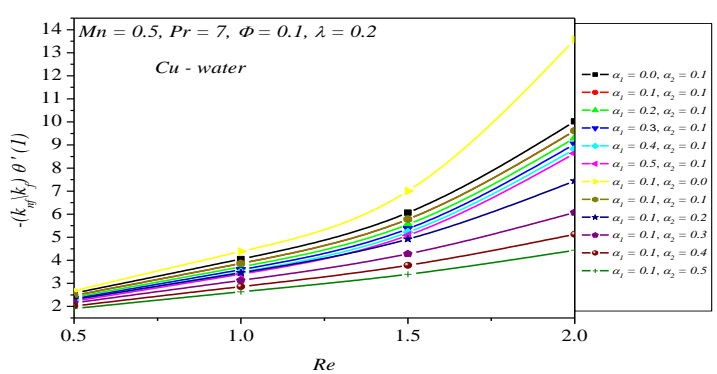

Fig. 14: Local Nusselt number $-\frac{k_{n f}}{k_{f}} \theta^{\prime}(1)$ under various values of $\operatorname{Re}, \alpha_{1} \& \alpha_{2}$. 
Table 1: Thermo Physical properties of water and nanoparticles

\begin{tabular}{|c|c|c|c|c|}
\hline & $\rho\left(\mathrm{kg} / \mathrm{m}^{3}\right)$ & $\mathrm{c}_{p}(\mathrm{j} / \mathrm{kgK})$ & $\mathrm{k}(\mathrm{W} / \mathrm{mK})$ & $\beta \times 10^{5}\left(\mathrm{~K}^{-1}\right)$ \\
\hline Pure water & 997.1 & 4179 & 0.613 & 21 \\
\hline $\begin{array}{c}\text { Copper } \\
(\mathrm{cu})\end{array}$ & 8933 & 385 & 401 & 1.67 \\
\hline $\begin{array}{c}\text { Silver } \\
(\mathrm{Ag})\end{array}$ & 10500 & 235 & 429 & 1.89 \\
\hline $\begin{array}{c}\text { Alimina } \\
\left(\mathrm{Al}_{2} \mathrm{O}_{3}\right)\end{array}$ & 3970 & 765 & 40 & 0.85 \\
\hline $\begin{array}{c}\text { Titanium } \\
\text { Oxide } \\
\left(\mathrm{TiO}_{3}\right)\end{array}$ & 4250 & 686.2 & 8.9538 & 0.9 \\
\hline
\end{tabular}

Table 2: Comparison of the skin friction coefficient $f^{\prime \prime}(1)$ for several values of $M$ when $\operatorname{Re}=10, \operatorname{Pr}=7, \alpha_{1}=\alpha_{2}=\Phi=0$ for clear fluids.

\begin{tabular}{|c|c|c|c|}
\hline $\mathbf{M}$ & $\begin{array}{c}\text { Present out } \\
\text { Comes }\end{array}$ & $\begin{array}{c}\text { Ishak et al. } \\
\mathbf{( 2 0 0 8 )}\end{array}$ & $\begin{array}{c}\text { Wang } \\
\mathbf{( 1 9 8 8 )}\end{array}$ \\
\hline 0 & -3.34447466 & -3.3444 & -3.34445 \\
0.01 & -3.34616380 & -3.3461 & \\
0.05 & -3.35290714 & -3.3528 & \\
0.1 & -3.36130711 & -3.3612 & \\
0.5 & -3.42742814 & -3.4274 & \\
1 & -3.50769113 & -3.5076 & \\
2 & -3.66154894 & -3.6615 & \\
5 & -4.08263292 & -4.0825 & \\
\hline
\end{tabular}

Table 3: Comparison of the Nusselt number $-\theta^{\prime}(1)$ for several values of $M$ and $\operatorname{Pr}$ when $\operatorname{Re}=10, \alpha_{1}=\alpha_{2}=\Phi=0$ for clear fluids.

\begin{tabular}{|c|c|c|c|c|c|c|}
\hline M & \multicolumn{3}{|c|}{$\operatorname{Pr}=0.7$ (air) } & \multicolumn{3}{|c|}{$\mathrm{Pr}=7$ (water) } \\
\hline & $\begin{array}{c}\text { Presenet } \\
\text { Out comes }\end{array}$ & $\begin{array}{l}\text { Ishak } \\
\text { et al. } \\
(2008)\end{array}$ & $\begin{array}{c}\text { Wan } \\
\text { g } \\
(198 \\
8)\end{array}$ & $\begin{array}{c}\text { Present } \\
\text { Out comes }\end{array}$ & $\begin{array}{l}\text { Ishak } \\
\text { et al. } \\
\text { (2008) }\end{array}$ & $\begin{array}{c}\text { Wan } \\
\mathrm{g} \\
(198 \\
8) \\
\end{array}$ \\
\hline 0 & 1.56821175 & 1.5687 & 1.56 & 6.15799699 & 6.1592 & 6.16 \\
\hline 0.01 & 1.56821175 & 1.5693 & & 6.15760797 & 6.1588 & \\
\hline 0.05 & 1.56586866 & 1.5665 & & 6.15606360 & 6.1573 & \\
\hline 0.1 & 1.54706606 & 1.5644 & & 6.15414072 & 6.1554 & \\
\hline 0.5 & 1.54706606 & 1.5478 & & 6.13903001 & 6.1402 & \\
\hline 1 & 1.52739974 & 1.5284 & & 6.12072591 & 6.1219 & \\
\hline 2 & 1.49103834 & 1.4924 & & 6.08570039 & 6.0864 & \\
\hline 5 & 1.40489535 & 1.4012 & & 5.98998891 & 5.9855 & \\
\hline
\end{tabular}

Table 4: Comparison of the skin friction coefficient $f^{\prime \prime}(1)$ for several values of $M, \operatorname{Re}$ when $\operatorname{Pr}=7, \alpha_{1}=\alpha_{2}=\Phi=0$ for clear fluids.

\begin{tabular}{|c|c|c|c|c|c|c|}
\hline M & \multicolumn{3}{|c|}{$\mathrm{Re}=1$} & \multicolumn{3}{|c|}{$\mathrm{Re}=5$} \\
\hline & $\begin{array}{l}\text { Presenet } \\
\text { Out comes }\end{array}$ & $\begin{array}{c}\text { Ishak } \\
\text { et al. } \\
\text { (2008) }\end{array}$ & $\begin{array}{c}\text { Wang } \\
(1988)\end{array}$ & $\begin{array}{l}\text { Present } \\
\text { Out comes }\end{array}$ & $\begin{array}{c}\text { Ishak } \\
\text { et al. } \\
\text { (2008) }\end{array}$ & $\begin{array}{c}\text { Wang } \\
(1988)\end{array}$ \\
\hline 0 & -1.1799527 & -1.178 & -1.17 & -2.4175881 & -2.417 & -2.4 \\
\hline 0.01 & -1.1838896 & -1.183 & & -2.4198870 & -2.419 & \\
\hline 0.05 & $\begin{array}{l}- \\
.1 .2068461 \\
\end{array}$ & -1.206 & & -2.4296412 & -2.429 & \\
\hline 0.1 & -1.2344238 & -1.234 & & -2.4417338 & -2.441 & \\
\hline 0.5 & -1.4269254 & -1.426 & & -2.5352329 & -2.535 & \\
\hline
\end{tabular}

Table 5: Comparison of the Nusselt number $-\theta^{\prime}(1)$ for several values of $M$ and $\operatorname{Re}$ when $\operatorname{Pr}=7, \alpha_{1}=\alpha_{2}=\Phi=0$ for clear fluids.

\begin{tabular}{|c|c|c|c|c|c|c|}
\hline M & \multicolumn{3}{|c|}{$\mathrm{Re}=1$} & \multicolumn{3}{|c|}{$\mathrm{Re}=100$} \\
\hline & $\begin{array}{l}\text { Presenet } \\
\text { Out comes }\end{array}$ & $\begin{array}{l}\text { Ishak } \\
\text { et al. } \\
(2008)\end{array}$ & $\begin{array}{c}\text { Wan } \\
\text { g } \\
(198 \\
8)\end{array}$ & $\begin{array}{c}\text { Present } \\
\text { Out comes }\end{array}$ & $\begin{array}{l}\text { Ishak } \\
\text { et al. } \\
\text { (2008) }\end{array}$ & $\begin{array}{c}\text { Wan } \\
\text { g } \\
(198 \\
8)\end{array}$ \\
\hline 0 & 2.05818236 & 2.0587 & 2.05 & 19.1185105 & 19.158 & 19.1 \\
\hline 0.01 & 2.05730215 & 2.0572 & & 19.1183972 & 19.158 & \\
\hline 0.05 & 2.05166521 & 2.0516 & & 19.1179439 & 19.158 & \\
\hline 0.1 & 2.04491803 & 2.0449 & & 19.1173773 & 19.157 & \\
\hline 0.5 & 1.99806483 & 1.9978 & & 19.1128512 & 19.153 & \\
\hline
\end{tabular}

Table 6: Impacts of the magnetic parameter for dissimilar types of nanofluids on skin friction coefficient when $\mathrm{Pr}$ $=7, \lambda=0.5, M n=0.5, \alpha_{1}=\alpha_{2}=0.1, \operatorname{Re}=1$.

\begin{tabular}{|c|c|c|c|c|}
\hline \multirow{2}{*}{$\Phi$} & \multicolumn{4}{|c|}{ Nanoparticles } \\
\cline { 2 - 5 } & $\mathrm{Cu}$ & $\mathrm{Ag}$ & $\mathrm{Al}_{2} \mathrm{O}_{3}$ & $\mathrm{TiO}_{2}$ \\
\hline 0.05 & -1.42316344 & -1.4430925 & -1.35645469 & -1.36037647 \\
\hline 0.1 & -1.65567312 & -1.69399633 & -1.52223751 & -1.53033129 \\
\hline 0.15 & -1.91631497 & -1.97304187 & -1.71291618 & -1.72555853 \\
\hline 0.2 & -2.21393912 & -2.29014377 & -1.93449470 & -1.95220372 \\
\hline
\end{tabular}

Table 7: Impacts of the magnetic parameter for dissimilar types of nanofluids on Nusset number when $\mathrm{Pr}$ =7, $\lambda=0.5, M n=0.5, \alpha_{1}=\alpha_{2}=0.1, \operatorname{Re}=1$.

\begin{tabular}{|c|c|c|c|c|}
\hline \multirow{2}{*}{$\Phi$} & \multicolumn{4}{|c|}{ Nanoparticles } \\
\cline { 2 - 5 } & $\mathrm{Cu}$ & $\mathrm{Ag}$ & $\mathrm{Al}_{2} \mathrm{O}_{3}$ & $\mathrm{TiO}_{2}$ \\
\hline 0.05 & 0.35145922 & 0.34413629 & 0.36038433 & 0.37044414 \\
0.1 & 0.26746447 & 0.25419041 & 0.28502729 & 0.30321561 \\
0.15 & 0.19588181 & 0.17965259 & 0.21926797 & 0.24356280 \\
0.2 & 0.13839452 & 0.12254558 & 0.16352744 & 0.19171135 \\
\hline
\end{tabular}

Table 8: Impacts of the thermal relaxation parameter for dissimilar types of nanofluids on Nusset number when $\mathrm{Pr}$ =7, $\Phi=0.1, M n=0.5, \alpha_{1}=\alpha_{2}=0.1, \operatorname{Re}=1$.

\begin{tabular}{|c|c|c|c|c|}
\hline \multirow{2}{*}{$\lambda$} & \multicolumn{4}{|c|}{ Nanoparticles } \\
\cline { 2 - 5 } & $\mathrm{Cu}$ & $\mathrm{Ag}$ & $\mathrm{Al}_{2} \mathrm{O}_{3}$ & $\mathrm{TiO}_{2}$ \\
\hline 0 & 0.18676319 & 0.15943472 & 0.24054617 & 0.28995665 \\
1 & 0.10815385 & 0.09858139 & 0.11930961 & 0.13613157 \\
5 & 0.03790460 & 0.03809433 & 0.03403085 & 0.03510397 \\
10 & 0.02210804 & 0.02291491 & 0.01890033 & 0.01886764 \\
\hline
\end{tabular}

\section{Conclusion}

A thorough research is done to solve the Cattaneo-christov heat flux model on the slip velocity and temperature jump on MHD flow of a nanofluid due to stretching cylinder. Cattaneo-Chirstov heat flux model is used to discover the heat relocation phenomena. Spectral relaxation method is applied to solve the governing nonlinear differential equations. The main findings of this problem are as follows.

- In order suppress the velocity field, which in turn cause the augmentation of the temperature field.

- $\quad$ The growing temperature jump parameter leads to the decline of temperature near the wall with the incline distance from the cylinder, as the effect of temperature jump parameter becomes smaller.

- The local Nusselt number and magnitude of skin friction decreases with the increasing slip velocity parameter.

- $\quad$ Temperature profile increases more rapidly in Fourier's law case rather than Cattaneo-Christov heat flux model.

- Selecting copper (for small nanoparticle solid volume fraction) and alumina (for large values of nanoparticle solid volume fraction) leads to the highest cooling performance for this issue.

\section{References}

[1] Choi SUS: Enhancing thermal conductivity of fluids with nanoparticles. The Proceedings of the 1995 ASME International Mechanical Engineering Congress and Exposition, San Francisco, USA. ASME, FED 231/MD 66 1995, 99-105.

[2] Wang X-Q \& Mujumdar AS (2007), Heat transfer characteristics of nanofluids. Int $J$ Therm Sci 46, 1-19.

[3] Das SK, Choi SUS, Yu W \& Pradeep T (2007), Nanofluids: Science and Technology NJ: Wiley.

[4] Khanafer K, Vafai K \& Lightstone M (2003), Buoyancy-driven heat transfer enhancement in a two-dimensional enclosure utilizing nanofluids. Int J Heat Mass Transfer 46, 3639-3653.

[5] Abu-Nada E (2008), Application of nanofluids for heat transfer enhancement of separated flows encountered in a backward facing step. Int J Heat Fluid Flow 29, 242-249. 
[6] Tiwari RJ \& Das MK (2007), Heat transfer augmentation in a twosided lid-driven differentially heated square cavity utilizing nanofluids. Int J Heat Mass Transfer 50, 2002-2018.

[7] Maïga SEB, Palm SJ, Nguyen CT, Roy G \& Galanis N (2005), Heat transfer enhancement by using nanofluids in forced convection flows. Int J Heat Fluid Flow 26, 530-546.

[8] Polidori G, Fohanno S \& Nguyen CT (2007) A note on heat transfer modelling of Newtonian nanofluids in laminar free convection. Int J Therm Sci 46, 739-744.

[9] Oztop HF \& Abu-Nada E (2008), Numerical study of natural convection in partially heated rectangular enclosures filled with nanofluids. Int J Heat Fluid Flow 29, 1326-1336.

[10] Nield DA \& Kuznetsov AV (2009), The Cheng-Minkowycz problem for natural convective boundary-layer flow in a porous medium saturated by a nanofluid. Int J Heat Mass Transfer 52, 5792-5795.

[11] Kuznetsov AV \& Nield DA (2010), Natural convective boundarylayer flow of a nanofluid past a vertical plate. Int J Therm Sci, 49, 243-247.

[12] Buongiorno J (2006), Convective transport in nanofluids. ASME J Heat Transfer 128, 240-250.

[13] Gangadhar K, Kannan T \& Jayalakshmi P, Magnetohydrodynamic micropolar nanofluid past a permeable stretching/shrinking sheet with Newtonian heating, J Braz. Soc. Mech. Sci. Eng., DOI 10.1007/s40430-017-0765-1

[14] J.B.J. Fourier (1822), Théorie Analytique De La Chaleur, Paris.

[15] C. Cattaneo (1948), Sulla conduzione del calore, Atti Semin. Mat. Fis. Univ. Modena Reggio Emilia 3, 83-101.

[16] Franchi F \& Straughan B. (1994), Thermal convection at low temperature, J. Non- Equilibr. Thermodyn 19, 368-374.

[17] Christov C.I. (2006), On frame indifierent formulation of the Maxwell-Cattaneo model of finite- speed heat conduction, Mech. Res. Commun. 36, 481-486.

[18] Han S, Zheng L., Li C \& Zhang X (2014), Coupled flow and hea transfer in viscoelastic fluid with Cattaneo-Christov heat flux model, Appl. Math. Lett. 38, 87-93.

[19] Straughan B. (2010), Thermal convection with the CattaneoChristov model, Int. J. Heat Mass Transfer 53, 95-98.

[20] Ciarletta M \& Straughan B (2010), Uniqueness and structural stability for the Cattaneo-Christov equations, Mech. Res. Commun. 37, 445-447.

[21] Hayat T, Imtiaz M, Alsaedi A \& Almezal S (2016), On CattaneoChristov heat flux in MHD flow of Oldroyd-B fluid with homogeneous-heterogeneous reactions, J. Mag. Magn. Mat. 401, 296-303.

[22] Hayat T, Farooq M, Alsaedi, A \& Alsolamy F (2015), Impact of Cattaneo-Christov heat flux in the flow over a stretching sheet with variable thickness, AIP Adv. 5, 087159 .

[23] Mustafa M, Mushtaq A, Hayat T \& Alsaedi A (2016), Rotating flow of magnetite-water nanofluid over a stretching surface inspired by non-linear thermal radiation, PLos One 10, e0149304.

[24] Waqas M, Hayat T, Farooq M,. Shehzad S.A \& Alsaedi A (2016), Cattaneo-Christov heat flux model for flow of variable thermal conductivity generalized Burgers fluid, J. Mol. Liq. 220, 642-648.

[25] Abbasi F.M \& Shehzad S.A (2016), Heat transfer analysis for three-dimensional flow of Maxwell fluid with temperature dependent thermal conductivity: application of Cattaneo -Christov heat flux model, J. Mol. Liq. 220, 848-854.

[26] Hayat T, Khan M.I, Farooq M, Alsaedi A, Waqas M \& Yasmeen $\mathrm{T}$ (2016), Impact of Cattaneo - Christov heat flux model in flow of variable thermal conductivity fluid over a variable thicked surface, Int. J. Heat Mass Transfer 99, 702 - 710.

[27] Li J, Zheng L \& Liu L (2016), MHD viscoelastic flow and hea transfer over a vertical stretching sheet with Cattaneo-Christov heat flux effects, J. Mol. Liq. 221, 19-25.

[28] Hayat T, Khan M.I, Farooq M, Yasmeen T \& Alsaedi A (2016), Stagnation point flow with Cattaneo-Christov heat flux and homogeneous-heterogeneous reactions, J. Mol. Liq. 220, 49 - 55.

[29] Liu L, Zheng L, Liu F \& Xinxin Zhang (2016), Anomalous convection diffusion and wave coupling transport of cells on comb frame with fractional Cattaneo-Christov flux, Commun. Nonlinear Sci. Numer. Simul. 38, 45-58.

[30] Reddy J.V.R, Sugunamma V, Sandeep N (2016), Cross diffusion effects on MHD flow over three different geometries with Cattaneo-Christov heat flux, J. Mol. Liq. 223, 1234-1241.

[31] Hayat T, Zubair M, Ayub M, Waqas M \& Alsaedi A (2016), Stagnation point flow towards nonlinear stretching surface with Cattaneo-Christov heat flux, Eur. Phy. J. Plus 131, 355.
[32] Tanveer, S. Hina, T. Hayat, M. Mustafa \& B. Ahmad, Effects of the Cattaneo - Christov heat flux model on peristalsis, Eng. Appl. Comput. Fluid Mech. 10, 375-385.

[33] Nadeem S \& Muhammad N (2016), Impact of stratification and Cattaneo-Christov heat flux in the flow saturated with porous medium, Mol. Liq., http://dx.doi. org/10.1016/j.molliq.2016.10.006.

[34] Hayat T, Qayyum S, Imtiaz M \& Alsaedi A, Flow between two stretchable rotating disks with Cattaneo-Christov heat flux model, Results in Physics 7, 126-133

[35] Raju CSK, Kiran Kumar VMSS, Varma SVK, Madaki AG \& Durga Prasad P, Transpiration Effects on MHD Flow Over a Stretched Cylinder with Cattaneo-Christov Heat Flux with Suction or Injection, Arab J Sci Eng., DOI 10.1007/s13369-017-2687-8

[36] Turkyilmazoglu, M (2011), Multiple solutions of heat and mass transfer of MHD slip flow for the viscoelastic fluid over a stretching sheet. International Journal of Thermal Sciences 50, 2264 2276.

[37] Freidoonimehr, N., Rashidi, M. M., Mahmud, S \& Nazari, F (2014), Slip effects on MHD stagnation point flow and heat transfer over a porous rotating disk. Physical Science International Journal $4,34-50$.

[38] Turkyilmazoglu, M (2011), Analytic heat and mass transfer of the mixed hydrodynamic/thermal slip MHD viscous flow over a stretching sheet. International Journal of Mechanical Sciences 53 886-896.

[39] Mukhopadhyay, S (2013), Slip effects on MHD boundary layer flow over an exponentially stretching sheet with suction/blowing and thermal radiation. Ain Shams Engineering Journal 4, 485-491.

[40] Malvandi, A., Hedayati, F., \& Ganji, D. D (2014), Slip effects on unsteady stagnation point flow of a nanofluid over a stretching sheet. Powder Technology 253, 377-384.

[41] Turkyilmazoglu, (2012) Dual and triple solutions for MHD slip flow of non-Newtonian fluid over a shrinking surface. Computers and Fluids 70, 53-58.

[42] Bhattacharyya, K., Mukhopadhyay, S., \& Layek G. C (2013), Similarity solution of mixed convective boundary layer slip flow over a vertical plate. Ain Shams Engineering Journal 4, 299-305.

[43] Rashidi, M. M., Kavyani, N \& Abelman, S (2014), Investigation of entropy generation in MHD and slip flow over a rotating porous disk with variable properties. International Journal of Heat and Mass Transfer 70, 892-917.

[44] Mukhopadhyay, S (2013), MHD boundary layer slip flow along a stretching cylinder. Ain Shams Engineering Journal 4, 317-324.

[45] Kiran Kumar RVMSS, Vijaya Kumar Varma S, Raju CSK, Ibrahim SM, Lorenzini G \& Lorenzini E, Magnetohydrodynamic 3D slip flow in a suspension of carbon nanotubes over a slandering sheet with heat source/sink, Continuum Mech. Thermodyn., DOI 10.1007/s00161-017-0563-0

[46] Wang CY (1988), Fluid flow due to a stretching cylinder. Phys Fluids 31, 466-468

[47] Aminossadati SM, Ghasemi B (2009), Natural convection cooling of a localized heat source at the bottom of a nanofluid-filled enclosure. Eur J Mech B Fluids 28,630-640

[48] Motsa SS and Makukula ZG, (2013), On spectral relaxation method approach for steady von kárman flow of a reiner-rivlin fluid with joule heating, viscous dissipation and suction/injection. Cent. Eur. J. Phys., 11(3), 363-374.

[49] Kameswaran P, Sibanda P, and Motsa SS, (2013), A spectral relaxation method for thermal dispersion and radiation effects in a nanofluid flow. Boundary Value Problems, 242.

[50] Ishak A, Nazar R \& Pop I (2008), Magnetohydrodynamic (MHD) flow and heat transfer due to a stretching cylinder. Energy Convers Manag 49, 3265-3269. 